\title{
O MODELO INTERSUBJETIVO DO SI MESMO PRODUZIDO SOCIALMENTE: MEAD, EDUCAÇÃO E LUTA POR RECONHECIMENTO*
}

\author{
Artur José Renda Vitorino ${ }^{1}$ \\ Bruna Coden da SiLva ${ }^{2}$
}

\begin{abstract}
RESUMO: A partir das interpretaçóes dos filósofos Jürgen Habermas e Axel Honneth do modelo intersubjetivo do si mesmo produzido socialmente, conforme elaborado por G. H. Mead, defende-se a necessidade de incorporar os preceitos de intersubjetividade, reconhecimento e democracia em uma concepçáo de educaçáo que, com base no pensamento cooperativo e comunitário, ensine o agir democrático — orientado para a resolução consensual de problemas e embasado no reconhecimento intersubjetivo entre os indivíduos.
\end{abstract}

Palavras-chave: Educação. Comunicação intersubjetiva. Luta por reconhecimento.

\section{THE INTERSUBJECTIVE MODEL OF THE SELF SOCIALLY PRODUCED: MEAD, EDUCATION AND STRUGGLE FOR RECOGNITION}

Abstract: Based on the interpretations of the philosophers Jürgen Habermas and Axel Honneth of the intersubjective model of the socially constructed self, as shown by G. H. Mead, we defend the need to include the concepts of intersubjectivity, struggle for recognition and democracy within a conception of education that, based on cooperative and communitarian thought, teaches democratic action - which will be orientated toward a consensual resolution of problems and based on an intersubjective recognition among individuals.

Keywords: Education. Intersubjective communication. Struggle for recognition.

\footnotetext{
*Este artigo é fruto do projeto de pesquisa "Educação e o modelo intersubjetivo do Eu produzido socialmente: uma leitura de G. H. Mead à luz da luta por reconhecimento" que foi apoiada com bolsa do Fundo de Apoio à Iniciação Científica (FAPIC)/Reitoria da Pontifícia Universidade Católica de Campinas (PUC-Campinas), realizada pela co-autora, no ano de 2016.

${ }^{1}$ Pontifícia Universidade Católica de Campinas (PUC-Campinas) - Campinas (SP), Brasil.

E-mail: arturvitorino@puc-campinas.edu.br

${ }^{2}$ PUC-Campinas, Bolsista do Fundo de Apoio à Iniciação Científica - Campinas (SP), Brasil.

E-mail: brunacoden@outlook.com

DOI: 10.1590/ES0101-73302017167323
} 


\section{LE MODÈLE INTERSUBJECTIF DU «MOI» SOCIALEMENT CONSTRUIT: MEAD, L'ÉDUCATION ET LA LUTTE POUR LA RECONNAISSANCE}

RÉSUMÉ: Dans le cadre de l'interprétation des philosophes Jürgen Habermas et Axel Honneth du modèle intersubjectif du «moi» socialement construit, ainsi démontré par G. H. Mead, nous soutenons le besoin d'inclusion des concepts d'intersubjectivité, de la lutte pour la reconnaissance et la démocratie, au sein de la conception d'une éducation qui, basée sur la mentalité coopérative et communautaire, enseigne l'action démocratique, en s'orientant donc vers les résolutions consensuelles des problèmes et en se basant sur la reconnaissance intersubjective entre individus.

Mots-clés: Éducation. Communication intersubjective. Lutte pour la reconnaissance.

\section{A educação e o paradigma da comunicação}

A

educação, independentemente da forma, do recipiente ou da linguagem, é uma constante inegável na história da vida humana; criada e construída por nós mesmos, a educação é também aquilo que nos constrói, que permite a renovação e transformação do conhecimento, que fornece a base para o florescer do si mesmo social, e é o meio a partir do qual a sociedade dialoga consigo mesma, critica a si mesma e modifica as suas estruturas de entendimento.

A importância prática do educar revela a necessidade de um conceito de educação que lide com noçóes de cooperação que, com base no reconhecimento intersubjetivo, tenham como objetivo proporcionar à sociedade democrática uma possibilidade de "regeneração de seus próprios fundamentos morais" (HONNETH, 2013, p. 552). Essa regeneraçáo implica a constante renovaçáo normativa de preceitos morais, formas sociais e hábitos individuais, acompanhando a dinâmica da vida em sociedade e visando, necessariamente, à reformulação, por sujeitos de direito, do mundo discursivo, ampliando o protagonismo social e construindo formas sociais que tenham base no respeito à subjetividade humana.

Nesse sentido, a psicologia social de George H. Mead oferece o suporte teórico para a compreensão da construção do si mesmo no interior do processo social e da sua natureza inerentemente intersubjetiva. Essa natureza é necessariamente refletida na sociedade (formada ao mesmo tempo em que se forma o ego individual) e na maneira como pensamos a formação educacional do indivíduo. $\mathrm{Na}$ prática, uma educação que se queira intersubjetiva pode tomar como caminho metodológico uma teoria que englobe um diálogo entre a Filosofia e a Pedago- 
gia, cuja viabilização, entretanto, necessitaria a crítica e a ampliação dos conceitos de racionalidade e ação. Isso é feito, a título de exemplo, por Jürgen Habermas em sua teoria do agir comunicativo que, pensando a partir de Mead, inclui na compreensão desses conceitos a interação mediada simbolicamente. $\mathrm{O}$ conceito simbólico-interacionista da ação de Mead permite a superação da visão introspectivo-individual e metódico-experimental, tornando mais abrangente a forma de se enxergar as relaçóes do ser humano com o mundo e com si mesmo. Essa superação permite a crítica à filosofia da consciência e a libertação das teorias da consciência de aporias metafísicas, aceitando "a incorporação de recursos conceituais que abram novas possibilidades à tarefa de fundamentação de uma teoria crítica da sociedade" (DALBOSCO, 2012, p. 228).

O conceito de racionalidade - presente em Mead, quando teoriza sobre a inteligência reflexiva, e em Habermas, quando escreve sobre a racionalidade comunicativa inerente à interaçấo social - possui certo apelo se consideramos, como considerava Mead, que a existência humana é pautada pela resoluçáo cooperativa de problemas, o que implica o agir racional e o reconhecimento mútuo da subjetividade de cada sujeito da interação. Dessa maneira, a teoria da argumentação, como exposta por Habermas, pode oferecer ferramentas para a coordenação racional de açóes para um fim democrático no contexto de uma interação entre sujeitos sociais. Axel Honneth, por sua vez, reatualizando a "luta por reconhecimento" de Hegel por meio da psicologia social de Mead, pensa uma teoria da modernidade que intenta localizar o conflito como cerne das formas sociais e se vê interessada "nos conflitos e nas lutas sociais enquanto fundamentos sociocomunicativos da crítica" (ALEXANDRE; RAVAGNANI, 2013, p. 175), dando espaço, assim, à prática democrática, com ênfase em modelos de liberdade e autorrealizaçáo, disponível a todos os sujeitos inseridos em um mesmo mundo discursivo. Essa prática, entretanto, ainda não se faz universal, e cabe ao educador conceber uma teoria da educação que privilegie a luta por reconhecimento na construção de uma sociedade na qual todos os indivíduos, reconhecendo-se intersubjetivamente, possam participar da edificação e renovação de estruturas sociais ultrapassadas, dando espaço para uma concepção vigente de cooperação social que reflita, politicamente, em instituiçóes sociais inclusivas.

\section{A constituição interacional do self para Mead}

George $\mathrm{H}$. Mead pensa os processos de individuação e socialização (ligados entre si e codependentes) sem fazer uso da simplificação inerente ao enquadramento destes no determinismo, seja individualista ou coletivista. A herança de Mead é a mudança de foco de um modelo teórico de individuação, centrado na consciência reflexiva individual, para um modelo que visualiza a construção social do indivíduo por meio da ação simbólica interacional — ou seja, um modelo 
que entende a individuação como autoentendimento e autorrealização mediados intersubjetivamente. No que se refere ao estudo e à compreensão do surgimento do si mesmo, para Mead é necessário que sujeitos conscientizem-se de si mesmos e de sua própria subjetividade por meio da interação. É apenas a partir do protagonismo na interação que é possível visualizar os mecanismos internos que fazem surgir a consciência do si mesmo subjetivo. O sujeito, nesse sentido, só pode alcançar uma consciência do significado social de suas açóes quando estiver ciente do sentido de seu comportamento em relação a outro indivíduo — ou seja, quando for capaz de ver a si mesmo como um objeto, o que o auxiliaria a enxergar o seu "eu", ou self, por meio dos olhos de outro. Quando a pessoa entende o significado de suas próprias açôes e reaçôes, ela chega à autoconsciência.

O si mesmo $(s e l f)$, desenvolvido por intermédio do processo da linguagem, não é algo individual, que se inicia sozinho, e sim algo que é gerado pelo mundo social. $\mathrm{O}$ emergir do si mesmo se dá mediante interação e comunicação, características-chave da vida social, e este si mesmo tem a característica de ser um objeto de si. Para que seja possível haver um conduto racional, é necessário que a pessoa consiga ver-se fora de si, tornando-se, dessa forma, um objeto. Sem nos entendermos objetivamente, para Mead, é impossível que consigamos agir racionalmente e inteligentemente.

A partir dessa percepção, verifica-se que a experiência do indivíduo consigo mesmo se dá a partir dos pontos de vista de indivíduos do mesmo grupo social e do ponto de vista generalizado do grupo social ao qual o sujeito pertence. $\mathrm{O}$ indivíduo, então, compreende a sua própria existência como alguém que possui uma identidade específica apenas a partir do momento em que se considera um objeto, o que só acontece quando adota as atitudes dos outros (take the attitude of the other) dentro de um contexto de experiência no qual todos os participantes do processo estão inseridos. A comunicação, nesse sentido, torna-se a ponte por meio da qual o indivíduo consegue tomar consciência de si mesmo. Tendo o seu início, para Mead, mediante gestos - a fase do ato social que faz sentido, intersubjetivamente, para todos os participantes da interação, e que, ao fazer idêntico sentido para todos os participantes, torna-se o simbolo, que seria a base da linguagem humana -, a comunicação é direcionada não somente para os outros, mas também para si mesmo.

O si mesmo, portanto, é uma estrutura social que emerge do processo da experiência social, e é impossível conceber a possibilidade de um si mesmo que surja de maneira solitária, não sendo fruto de interaçôes. É apenas a partir da consciência de si que um gesto se torna um símbolo que possui significância, e aquilo que um gesto significa (meaning) só é entendido por meio da resposta que o outro dá a esse mesmo gesto. É por meio da reflexividade do indivíduo acerca de si mesmo que o processo social é trazido à experiência dos indivíduos envolvidos nele; e é por meio da reflexividade que o indivíduo consegue adotar a atitude do outro, ajustando-se ao processo e podendo modificar o seu resultado. 
Além da comunicação, Mead afirma que a atividade de jogar (game) e a brincadeira (play) também são fatores de plano de fundo na gênese do si mesmo. Enquanto crianças, somos o centro de nosso próprio mundo, e as opiniōes externas sobre o nosso self são, para nós, irrelevantes. Conforme crescemos, entretanto, a maneira como as outras pessoas nos enxergam começa a se tornar importante, e essa consciência da importância da visão do outro acerca de quem se é ocorre a partir de três fases. No primeiro estágio, preliminar, as crianças interagem por intermédio da imitação. Imitação não é a interação per se; entretanto, conforme a criança cresce ela passa a focar mais em comunicaçấo: os gestos e a troca de símbolos.

É durante o play stage, o segundo estágio, que a criança se torna consciente da importância das relaçóes sociais, e isso reflete na sua tendência de fingir ser outras pessoas (pretend play), tentando colocar-se no ponto de vista daquele que imita. O foco, nesse estágio, é a tomada do papel do outro e o agir com base no que a criança pensa ser o ponto de vista do outro. No último estágio, o game stage, o entendimento de interaçóes sociais pela criança se torna ainda mais desenvolvido; se, durante o play stage, a criança é capaz de considerar as atitudes, as crenças e os comportamentos das pessoas mais próximas a ela, durante o game stage ela passa a compreender as atitudes, as crenças e os comportamentos daquele que Mead chama de o outro generalizado: a sociedade em si. A criança percebe que as pessoas agem não somente com base no que elas mesmas acreditam, mas também com base no que a sociedade, de modo geral, espera delas. A partir de então, a criança passa a ser influenciada pela percepção dos outros acerca de si mesma.

Essa influência de outros na vida da criança, principalmente dos significant others (pessoas de relativa importância, como pais, parentes ou amigos), é o que leva ao desenvolvimento do $I$ e do $M e$, que Mead considera como as duas partes do si mesmo. O Me, em termos simples, é o si mesmo construído a partir da visão que imaginamos que o outro generalizado tem de nós, e é construído, durante a nossa vida, por meio de interaçôes com outras pessoas. O I é a identidade individual, que pode ou não ser afetada e controlada pela influência do $M e$. O Me é a nossa identidade social, e o $I$ é a nossa identidade criativa; ou seja, o $I$ é uma resposta ao $M e$. O si mesmo, para Mead, é o equilíbrio entre o $I$ e o $M e$ - o nosso self criativo e dinâmico, e o nosso self que se pauta pela internalização das normas da sociedade em que vivemos.

É desse generalizar as atitudes de todos os grupos sociais aos quais o indivíduo pertence - habilidade que se forma durante o game stage do desenvolvimento da criança - que nasce o outro generalizado, a forma social que dá à pessoa a unidade do seu self. A atitude do outro generalizado é, portanto, a atitude de toda a comunidade. Ademais, afirma Mead, é apenas mediante a internalização das atitudes do outro generalizado que o indivíduo pode pensar, e é com base 
na existência de um outro generalizado (ou outros generalizados) que o universo de discurso, no qual existe um sistema de significados sociais comuns, forma-se (MEAD, 1974, p. 156).

Quando o sujeito, internamente, aprende a generalizar as expectativas normativas do grupo no qual está inserido, ele se torna capaz de participar de interaçôes que são reguladas por normas sociais subjetivas, pois interiorizou as expectativas daqueles ao seu redor, assim como as suas obrigaçóes. É a partir dessa etapa que o sujeito se concebe como um alguém que faz parte de uma sociedade organizada; e só aí ele é, então, capaz de desenvolver uma identidade completa. O sujeito, portanto, deve ser e se sentir aceito pela sociedade, o que se torna um tipo de reconhecimento. A proposta de Mead é a de um reconhecimento mútuo; a identidade do sujeito é reconhecida na comunidade à medida que o sujeito também reconhece a identidade de outros.

Com a adoção da perspectiva do outro generalizado, quando dois sujeitos interagem um com o outro, ambos estão cientes, de maneira recíproca, de quais são as suas obrigaçóes com relação ao outro. Essa experiência de reconhecimento, quando se é uma pessoa de direito que é aceita pela sua comunidade, permite ao sujeito ter uma visão positiva de si mesmo. A próxima etapa desse reconhecimento é o reconhecimento mútuo de que cada pessoa possui a própria individualidade — ou seja, o reconhecimento intersubjetivo.

\section{Mead, para Habermas}

Os processos complementares de individuação e socialização, assim como teorizados por Mead em suas palestras acerca do si mesmo formado socialmente, são de grande interesse para Jürgen Habermas, que vê no pensamento meadiano a base para uma teoria da evolução humana que deixa de lado a imagem do indivíduo isolado em favor "da relação intersubjetiva de indivíduos que se socializam por meio da comunicação e se reconhecem mutuamente" (PENITENTE, 2013, p. 207). O si mesmo - possuinte de um núcleo intersubjetivo, visto que se forma dentro do processo social - nasce por meio da interaçáo mediada pela linguagem. Essa mediação é o ponto importante da inovação de Mead; também é o ponto que Habermas acredita ser o cerne da mudança de paradigma que a teoria meadiana arquitetou: se o si mesmo surge, no contexto social, da interação que ocorre por meio da comunicação, Mead rompe com a ideia de um si mesmo puro que observa e julga o mundo externo objetivamente, dando força à ideia de um si mesmo que não somente depende da interação, mas, principalmente, que não existiria sem a presença de outras pessoas.

É a psicologia social de Mead que permite a apreensão do processo de individuação humano e a formação do si mesmo codependente, trazendo a iden- 
tidade do sujeito para o campo da linguagem e da comunicaçáo por meio da criaçáo de um $\mathrm{Me}$ que age e pensa influenciado pelo ponto de vista de um outro que o observa. A transposição da consciência para o campo linguístico permite a recuperação da racionalidade humana como pressuposto para as interaçóes de fala, ao mesmo tempo em que permite, ainda, a verificação de que a comunicação só existe quando os símbolos utilizados pelos indivíduos da interação possuem idêntico significado para todos - ou seja, possuem uma identidade específica. Se o reconhecimento intersubjetivo é uma faceta indispensável da linguagem, também o é no que se refere ao processo social e à formação do si mesmo.

Para Habermas (2012b), a superação do modelo sujeito-objeto, o qual constituía no século XX a base da filosofia da consciência, deve necessariamente acontecer por meio da emergência de um agir comunicativo que tenha base em uma intersubjetividade ancorada na linguagem. Para a criaçáo da sua teoria do agir comunicativo, Habermas se apoia, entre outros, em Mead, em cuja teoria há a uniáo das duas linhas de crítica à filosofia da consciência. A teoria da comunicação de Mead não adota um conceito de linguagem reducionista: pelo contrário, abrange o agir comunicativo, não se limitando ao comportamento exterior, como o faria se concebida por um autor clássico behaviorista, e, em igual medida, não se limitando à interioridade, como se enunciada por estudiosos da consciência. No agir comunicativo de Mead, a linguagem (símbolos linguísticos e logomórficos) é o veiculo mediador e a coordenadora de atividades e açóes.

O modelo seguido por Mead, afirma Habermas, não tem a ver com a reação de um organismo individual a estímulos, e sim concentra-se na interação entre dois ou mais organismos (HABERMAS, 2012b, p. 9). Sendo a psicologia de Mead social, as suas análises do surgimento da consciência, da linguagem e da sociedade partem de uma concepção do ser humano como ser inerentemente interativo. O foco de Mead, então, é a compreensão das características estruturais da interação mediada por símbolos, visto que estes, quando são conhecidos intersubjetivamente entre os participantes de uma interação, possibilitam uma nova forma de comunicação que difere da comunicação por gestos.

Para Mead, a linguagem que se utiliza de gestos é a fase inicial de uma evolução da linguagem que possui duas etapas, denominadas por Habermas como etapa de uma linguagem mediante sinais simbólicos e etapa da fala diferenciada em proposiçôes (HABERMAS, 2012b, p. 12). Gestos significantes são os símbolos simples que têm o mesmo significado para dois participantes de uma interação. A linguagem, por sua vez, surge conforme os participantes de uma interação internalizam a linguagem de seus gestos, tornando disponível a todos o entendimento nas interaçóes. Há duas etapas no processo do surgimento da linguagem. Na primeira, $o$ advento de uma linguagem de sinais transforma o significado objetivo de padróes de comportamento típicos (por exemplo, fugir, atacar ou procriar) em significados simbólicos, tornando-os acessíveis a um entendimento entre os participantes da 
interação; é a passagem da interação mediada por gestos para a interação mediada simbolicamente, que, a partir da teoria do significado, Mead interpreta como uma semantização de significados naturais. A segunda etapa é aquela na qual papéis sociais revelam aos participantes o significado natural de sistemas de comportamento; o significado é, então, tomado como normativamente obrigatório - essa é a etapa do agir regulado por normas.

Naturalmente, existem etapas na evolução da interação mediada por gestos até uma interação mediada por símbolos. Mead tenta explicar essas etapas por meio do conceito de adotar a atitude do outro (taking the attitude of the other); para Habermas, se Mead quer explicar a maneira como a interação mediada por símbolos surge da interação mediada por gestos por meio do mecanismo de adoção de atitudes, é necessário que ele demonstre como a comunicação de gestos passa para a comunicação regulada por sinais linguísticos; como o organismo adota os papéis de falante e destinatário; e como atos comunicativos se distinguem de açóes não comunicativas, o que Mead não faz. Há uma falha, então, na análise meadiana, visto que ele não distingue o nível da interação mediada por símbolos do nível da interação mediada pela linguagem e direcionada por normas.

Dessa maneira, ao analisar os três atos do processo de adoção de atitudes, intimamente conectado ao processo de surgimento da linguagem, Habermas verifica que Mead não elabora com suficiente precisão e detalhamento o terceiro passo ou categoria. No primeiro ato, os participantes da interaçáo vinculam ao mesmo gesto uma mesma interpretação. No segundo ato, os participantes aprendem a utilizar um gesto com intenção comunicativa, estabelecendo uma relação recíproca entre quem ouve e quem fala. A partir desse estágio, os participantes "aprendem a distinguir entre açóes comunicativas endereçadas a um alter e açóes que se orientam pelas consequências ou que produzem algo" (HABERMAS, 2012b, p. 28). Esse aprendizado proporciona a base para o terceiro estágio, em que o ego e o alter — mediante interaçóes nas quais o ego realiza um gesto na expectativa de que o alter a ele reaja de certa maneira, ou seja, antecipando a reação comportamental do alter — podem ser surpreendidos por ações ou reaçóes inesperadas, resultando em uma comunicação malsucedida, o que gera uma terceira situação, em que sujeitos de um diálogo expressam descontentamento com o erro comunicativo e, adotando para si a crítica do outro, "criam regras para a utilização de simbolos. [...] Assim, formam-se convençóes de significado e símbolos que podem ser empregados com significado idêntico" (HABERMAS, 2012b, p. 29).

É esse terceiro estágio que explicaria o surgimento da linguagem mediante a criação de regras para o uso de símbolos, que seriam idênticos e possuiriam o mesmo significado intersubjetivo, em uma interação, para dois ou mais participantes. Para Habermas, entretanto, Mead não explica com suficiente perspicuidade "a importância da internalização das tomadas de posiçáo de outro com relação à utilização 
falha de símbolos" (HABERMAS, 2012b, p. 30). Essa lacuna na teoria de Mead, afirma, pode ser suprida pela análise wittgensteiniana do conceito de regra.

Dito isso, o conceito de regra é importante para Habermas, pois na comunicação é necessário apreender a identidade de um significado, visto que símbolos que possuem significados constantes necessitam ser reconhecidos por aqueles que os utilizam. A identidade, entâo, é chave para esse reconhecimento e para a constância do significado, e ela "só pode ser garantida mediante a validade intersubjetiva de uma regra, a qual circunscreve 'convencionalmente' o significado de um sinal" (HABERMAS, 2012b, p. 32). Dessa maneira, a passagem para uma interação mediada por símbolos necessita a constituição de um comportamento regido por regras e orientado por convençóes de significado. A capacidade de entender (e seguir) uma regra não só possibilita a compreensão de açóes simbólicas, mas também revela a nossa compreensão acerca da identidade de um significado (meaning) que, assim como a identidade de uma regra, depende de uma validação intersubjetiva.

Wittgenstein intenta demonstrar o nexo existente entre a identidade e a validade de regras, o que leva Habermas a verificar que a validade de uma regra repousa na intersubjetividade de sua validade, o que torna possível a crítica e avaliação de um comportamento regido por regras (HABERMAS, 2012b, p. 35-36). Assim, Habermas apresenta um dos conceitos centrais de sua teoria do agir comunicativo: "Sem essa possibilidade da crítica recíproca, e do esclarecimento recíproco, capaz de levar a um consenso, não seria possível assegurar a identidade das regras" (HABERMAS, 2012b, p. 36). Nesse sentido, o conceito wittgensteiniano de regra permite-nos pensar que a capacidade de seguir regras depende de (e informa) a relação intersubjetiva entre interlocutores, os quais são capazes de avaliar comportamentos criticamente e aplicar símbolos cujos significados sejam idênticos. Ambos - regras e significados - necessitam, portanto, manter uma validade intersubjetiva.

Essa condição que dá base ao consenso, ao permitir que participantes de uma interação informem suas posiçóes críticas com relação a proposições de outros participantes, não é a única faceta importante do agir comunicativo: a racionalidade é, também, indispensável. Para Habermas, a racionalidade de algo é atribuída à sua capacidade de sofrer críticas e de se fundamentar. O que é racional permanece acessível a um julgamento objetivo, pois concretiza o saber, assim mantendo relação com os fatos. Uma asserção só pode ser racional quando se pretende chegar a um entendimento mútuo sobre alguma coisa com um ou mais participantes. A partir de uma posição fenomenológica da realidade, que enxerga o mundo como objetivo quando este se torna válido para uma comunidade de sujeitos capazes de agir e utilizar a linguagem, Habermas verifica que somente quem é imputável pode ser racional, e "só pode ser considerada imputável a pessoa que, como participante de uma comunidade de comunicação, seja capaz de 
orientar seu agir segundo pretensóes de validade intersubjetivamente reconhecidas" (HABERMAS, 2012a, p. 43).

A racionalidade comunicativa, dessa maneira, permite a coordenação cooperativa de açóes e a superação consensual de conflitos. A racionalidade não está ligada somente à capacidade de exteriorizar opinióes fundamentadas e lógicas, ou saber criticar e ser criticado, mas também envolve aprender a partir de erros ou fracassos, tornando-se, assim, capaz de renovar e fazer a manutenção do mundo externo, discursivo e compartilhado. Nesse sentido, as regras e as normas intersubjetivamente validadas existem para exteriorizar interesses comuns a todos os participantes, e "devem estar em condiçóes de encontrar o assentimento racional de todos os atingidos" (HABERMAS, 2012a, p. 50) no que se refere à busca pela verdade e pelo consenso. Portanto, a idealização de uma racionalidade comunicativa que serviria de base para uma educação que almeja o consenso democrático e é fundamentada na discussão argumentativa apoia-se em Mead e encontra o seu desenvolvimento em Habermas.

\section{Mead, por Honneth (e a partir da crítica ao paradigma da comunicação de Habermas)}

Honneth (2003) formula uma teoria da modernidade — partindo da noção de luta por reconhecimento, primeiramente apresentada por Hegel — que focaliza as esferas sociais e encontra no conflito, em primeiro lugar, o cerne da estrutura das relaçóes sociais e do movimento da história e, em segundo lugar, o norteador dos elementos fundamentais do social, que deve ensejar o reconhecimento intersubjetivo como lugar final.

O embasamento de sua teoria também provém, assim como a teoria do agir comunicativo de Habermas, da psicologia social de Mead; entretanto, diferentemente de Habermas, Honneth não enxerga na interação linguística o elemento estruturante da relação intersubjetiva, visto que entende que uma teoria crítica que possui o criticismo prático como condição constitutiva do conhecimento crítico (ALEXANDRE; RAVAGNANI, 2013, p. 157) precisa conceber um social mais amplo, sem deixar de lado a dinâmica dos conflitos sociais e a participação e ação transformadora de sujeitos sociais no mundo objetivo.

Para Honneth, a teoria do agir comunicativo de Habermas, que enfatiza o campo linguístico e fraciona o social em "mundo da vida" e "sistema", subordina o potencial do paradigma comunicativo à teoria sistêmica (apud ALEXANDRE; RAVAGNANI, 2013, p. 159), o que significa que a concepção de um sistema "puro" necessariamente considera patologias sociais como externas à racionalidade do mundo da vida, reduzindo o espaço de ação da crítica como ferramenta indispensável para a manutenção do mundo discursivo 
compartilhado, e não dando a importância que Honneth considera necessária às lutas que levam ao reconhecimento.

O que é de negativo nas práticas sociais - e que, portanto, é interno à racionalidade que estrutura o nosso modo de vida, e é interno, necessariamente, às estruturas sociais por nós construídas - tem o seu impacto diminuído na teoria de Habermas, resultando na exclusão do conflito social, tão intrínseco à vida humana que "até mesmo a comunicação se mostra estruturalmente conflituosa" (ALEXANDRE; RAVAGNANI, 2013, p. 160). A ênfase na motivação moral das lutas sociais não encontra espaço em uma teoria linguístico-discursiva, e apenas uma teoria que englobe a luta por reconhecimento, os conceitos de eticidade e espirito objetivo de Hegel e a psicologia social de Mead conseguiria "apresentar sistematicamente as estruturas sociais do reconhecimento, seus padróes e sua importância para a socialização e para a lógica moral dos conflitos sociais" (ALEXANDRE; RAVAGNANI, 2013, p. 161).

Honneth, retomando as concepçóes de $I$ e $M e$ de George H. Mead, percebe um atrito entre o $I$ que quer desobedecer e o $M e$ que quer pertencer, e encontra nesse atrito a base do conflito que explica o desenvolvimento moral de indivíduos e de sociedades. Há uma tensão entre as vontades internalizadas pelo $M e$ e a individuação pretendida pelo $I$, o que acaba resultando em um conflito moral entre sujeito e sociedade. Para Honneth, o vínculo que Mead estabelece entre o $I$ criativo e o processo de vida social significa que, historicamente, a acumulação de divergências morais entre indivíduos cria um sistema que força a permanente adaptação ao contínuo processo de individuação do sujeito. O processo de evoluçấo da sociedade, dessa maneira, tende à liberação da individualidade, e se dá com a progressiva ampliação daquilo que o âmbito jurídico reconhece: necessariamente, o aumento de liberdade para o sujeito expressar o seu $I$. O motor dessas mudanças é a luta, a partir da qual os sujeitos continuamente tentam ampliar a extensão de seus direitos, consequentemente tornando a liberação da individualidade uma "luta por reconhecimento de longo alcance" (HONNETH, 2003, p. 145).

A inclusão do potencial criativo do $I$ no seu entendimento da formação da identidade humana adiciona mais uma camada à tese de Mead. Agora, observase que o sujeito possui direitos e deveres; é cidadáo e membro de uma comunidade; o I é a reação do indivíduo à essa comunidade, e, portanto, é capaz de alterá-la. Surge, entretanto, um problema: se o potencial criativo do $I$ é contraposto ao $M e$, não basta que o sujeito interiorize as normas do outro generalizado para que se forme a sua identidade moral. Cria-se, então, não mais apenas uma contraposição, mas um verdadeiro atrito entre o $I$ que quer desobedecer e o $M e$ que quer pertencer, e para Mead, essa é a base do conflito que explica o desenvolvimento moral de indivíduos e, também, de sociedades. Há, portanto, uma tensão entre as vontades internalizadas pelo $\mathrm{Me}$ e a individuaçáo pretendida pelo $I$, o que acaba levando 
a um conflito moral entre sujeito e sociedade. É apenas a partir da existência de um $M e$ trabalhando em prol do $I$ que o sujeito passa a desejar novas formas de reconhecimento social.

Assim, tomando uma posição pós-metafísica de reconstrução pragmática que se aplica tanto ao convívio intersubjetivo quanto às formas de reconhecimento, e usando o pensamento meadiano como ponte teórica, Honneth atualiza Hegel a partir de uma fenomenologia empírica que, com o intuito de compreender a gramática do surgimento e a configuração dos movimentos sociais, intenta explicar a dinâmica moral inerente a essa estrutura, cuja motivação é o reconhecimento, lugar final de uma luta desencadeada pelo desrespeito aos direitos e à subjetividade humana. A preocupação maior de Honneth com os conflitos morais e comunicativos e como estes definem as relaçóes sociais e as construçóes institucionais, bases para os modelos de práticas democráticas - culmina em uma atualização dos conceitos de eticidade e de espírito objetivo postulados por Hegel. Essa atualização apresenta a delimitação conceitual de uma "eticidade democrática" que mantém o foco nas esferas sociais e propóe uma reconstrução normativa da realidade social, ancorada pela mobilização prática das estruturas e relações éticas da vida social, urdida por sujeitos autorrealizados que se reconhecem intersubjetivamente (ALEXANDRE; RAVAGNANI, 2013, p. 166). Nesse sentido, proposiçóes que se consideram universais devem ser deliberadas em conjunto por sujeitos cidadãos, respeitando e agindo com base nos diversos pontos de vista morais do grupo ou da comunidade, de modo a permitir "a possibilidade de articulação e reivindicação coletivas por reconhecimento, dignidade e justiça” (ALEXANDRE; RAVAGNANI, 2013, p. 173). Seria por intermédio da eticidade democrática, portanto, que sujeitos de direito se reconheceriam de maneira mútua em suas individualidades, sabendo-se capazes, todos, de laborar em prol de uma identidade coletiva.

\section{À guisa de fecho: construção do conceito de uma educação democrática}

Partindo dos preceitos de intersubjetividade, reconhecimento e democracia, como, então, incorporar as ideias de George H. Mead, Jürgen Habermas e Axel Honneth em uma concepção de educação que, com base no pensamento cooperativo, comunitário e com vistas à busca de soluçóes que beneficiem o todo, ensine o agir democrático, orientado para a resolução consensual de problemas, constituindo-se como base ao reconhecimento intersubjetivo entre os indivíduos?

A partir de Mead (1974), aprendemos que não existimos isoladamente, não somente no que se refere à vida social, mas também, e principalmente, no que se refere à formação do nosso si mesmo propriamente dito; a formação de nossas personalidades; e a maneira com que percebemos e enxergamos o mundo à nossa volta. A base de nossa existência é a interação com o outro, porque só nos per- 
cebemos como sujeitos e identidades separadas daquilo que é externo a partir da percepção e da tomada de posição do outro em toda a sua subjetividade interna.

Mead (1974) faz-nos compreender o caráter social da vida humana e a interdependência existente entre a formação do self(si mesmo) e a constituição da sociedade. A característica dinâmica da sociedade atual provém da infinita associação entre diferentes selves que aprendem com e modificam uns aos outros, necessariamente, então, também modificando e reconstruindo a sociedade ao seu redor. A existência humana é pautada na intersubjetividade, a ponto de a consciência, a mente, a comunicação, a sociedade e todos os processos que daí surgem, como os processos de individuação e socialização, possuírem, todos, núcleos intersubjetivos e simbólicos. Agir ou existir isoladamente são concepçóes falsas; portanto, visto que sempre carregamos o outro e a sociedade no intrínseco de nosso ser, nunca estamos sozinhos, pois a nossa existência é pautada na interação e comunicação com outras pessoas.

Ao pensar o conceito de inteligência reflexiva como aquilo que difere a espécie humana dos outros animais, Mead (1974) chega ao conceito complementar de racionalidade, que envolve a atitude dupla de, em primeiro lugar, considerar ou analisar um objeto e, em segundo, de agir sobre esse objeto. A nossa concepçáo de racionalidade, entretanto, revisada por Habermas (2012a) e Honneth (2003), reflete a sua verdadeira identidade como constructo social que náo depende da soberania do sujeito. Isto é, a racionalidade é formada por meio da troca mútua mediada pela linguagem — ou ainda, a comunicação entre indivíduos que possuem suas subjetividades particulares e que, ao se colocarem como passíveis de oferecer e receber críticas, mantêm-se abertos ao contínuo aprendizado a partir de erros e fracassos, bem como aptos a direcionar a sua racionalidade comunicativa à renovação do mundo de discurso que compartilham, realizando a manutenção das regras e normas que validam o existir em comunidade. $\mathrm{O}$ agir racional é capaz de engendrar açóes de forma cooperativa, apoiado no contexto e na necessidade da comunidade ou do grupo no qual se está inserido.

Ora, não é de se espantar que a educação tenha um caráter social e interativo para Mead. É a partir das relaçôes sociais, e por meio da capacidade da criança de ser social, que significados sáo criados, transformados e repensados, e a criaçáo e apreensão de novos significados é a base da educação. Mead retorna, repetidamente, à coordenação e à cooperação social como matrizes de uma educação que possui papel central na organização e manutenção da vida social (CASAGRANDE, 2014 , p. 89-91). Isso se une à concepção do agir racional com base na argumentação de Habermas e, ao mesmo tempo, à concepção de Honneth de uma eticidade democrática que reconstrói normativamente, pela via da luta por reconhecimento, o mundo discursivo-social. A resolução de problemas a partir da racionalidade e do diálogo intersubjetivo entre sujeitos cidadãos é característica importante de uma educação que é pensada em termos cooperativos, democráticos e consensuais. 
A partir de Mead (1974), pensamos a educação como uma forma social dinâmica e enérgica que, por meio de selves que estão constantemente crescendo, modificando-se e modificando o mundo à sua volta, mantém as esferas sociais em constante renovação - de conhecimento, de ferramentas, de conceitos e da forma societal em si. É a partir da educação que desenvolvemos a conduta moral, estabelecemos valores, criamos normas e atuamos com base em preceitos democráticos e universais, em um processo ativo de (re)construção do tecido social.

Já Honneth teoriza, com base em Kant, uma religação entre a teoria da democracia e a da educação, verificando que "[o] tipo de educação escolar, seus métodos e conteúdos, pode repercutir de maneira desejável na consistência de uma democracia, promovendo, por exemplo, a capacidade de cooperação e a autoestima individual" (HONNETH, 2013, p. 548). Honneth enxerga na educação um instrumento societal para a regeneração de nossos fundamentos morais; uma educação, entretanto, que não rejeite o conflito, a um só tempo, inerente à racionalidade que estrutura o mundo discursivo e a tudo aquilo de social que construímos, e que seja capaz de enfatizar as lutas sociais e os seus objetivos de melhoramento moral da espécie humana. Honneth, ademais, radicalizando a teoria de reconhecimento de Hegel, propóe "a reciprocidade radical como base de qualquer relacionamento social, capaz de recuperar os ideais de solidariedade e justiça social” (FLICKINGER, 2011, p. 223). A sua luta por reconhecimento, portanto, inclui uma revalorização do espírito de solidariedade, não nivelando diferenças, mas aceitando-as.

Para que se fuja de uma concepção instrumentalizadora de teoria da educação, é necessário que a resolução de problemas seja pensada ao mesmo tempo em que o indivíduo aprende a questionar a natureza - no que se refere a pensar e criticar a sua constituição - e a finalidade - ao perguntar-se a quem a resolução está direcionada — dos problemas solucionados (DALBOSCO, 2012, p. 195). Tal empreendimento implica uma interlocução da filosofia com a pedagogia, partindo da crítica dupla ao conceito metafísico clássico da filosofia e às tendências positivistas redutoras da pedagogia; passando por uma concepção de filosofia que se preocupa com questóes sociais atuais e uma pedagogia que compreende o aluno não como receptáculo, mas como construtor de conhecimento; e desembocando em um diálogo entre as duas teorias, que se dá mediante a transformação de questôes educacionais em problemas filosóficos, não forçadamente inserindo a filosofia na pedagogia per se, mas buscando questóes filosóficas existentes no interior do processo formativo-educacional humano (DALBOSCO, 2012, p. 186).

Nesse sentido, é interessante pensar a contribuiçáo habermasiana no que se refere ao agir racional, compreendendo que processos de aprendizado dependem de argumentaçóes entre participantes de uma interação intersubjetiva, capazes de criticar as proposiçóes de validade uns dos outros, pois é por meio da crítica que "angariamos conhecimentos teóricos e discernimentos morais, renova- 
mos e ampliamos a linguagem avaliativa e suplantamos autoenganos e dificuldades de entendimento" (HABERMAS, 2012a, p. 54-55). A racionalidade, nessa mesma linha, "continua sendo apenas casual quando não se liga à capacidade de aprender a partir de fracassos, a partir da refutação de hipóteses e do insucesso de algumas intervenções" (HABERMAS, 2012a, p. 49). Suplementando a tese de Mead que se refere à linguagem mediada simbolicamente e à linguagem mediada por normas, relembra-se a inclusão, por Habermas, do conceito de regra como pensado por Wittgenstein, que estrutura as relaçóes intersubjetivas que permitem o consenso e o diálogo. Pensar e agir de maneira crítica com base em regras mutuamente observadas é indispensável para a interação entre sujeitos que buscam a realização de um mesmo objetivo democrático.

Sem dúvidas, a transposição de um sujeito que existe em solidão para o foco em um $M e$ que se forma no interior da dimensão linguística da vida humana e que existe apenas em contextos de interação (HABERMAS, 1990, p. 196) é a herança de Mead para a filosofia e para a educação. A teoria de Mead, a partir da qual o si mesmo do indivíduo é formado por duas partes conectadas, o $I$ e o $M e$, é essencial para a concepção de um consenso com base na intersubjetividade. É apenas a interação que consegue fazer com que os sujeitos se conscientizem de si mesmos e de sua própria subjetividade, e o sujeito só é capaz de estar ciente da intersubjetividade de suas açóes a partir da existência de um objeto $M e$ na sua experiência interna, que coloca em evidência o I como uma forma de autoconsciência. Se a pessoa se conscientiza do que a sua açâo significa para o outro, ela é capaz de compreender a sua própria identidade e, mais que isso, compreender e respeitar a identidade do outro.

Isso nos leva ao consenso. Seja pela intervençáo de Mead ou de Habermas, o consenso é importante como o ideal a almejar, ou como a conduta a partir da qual se constroem resultados democráticos. Como o mundo discursivo, entretanto, é composto pela incessante interação entre diversos selves, é necessário manter em mente a complexidade da realidade social - e de todos os processos que dela resultam —, tornando impreterível a inclusão do conceito de luta por reconhecimento em uma teoria da educação que se queira democrática e que busque a constante renovação das formas sociais e da sociedade em geral. Uma educação, portanto, que tenha base na intersubjetividade, na cooperação e na constante renovação normativa não é somente possível, como se faz integralmente necessária em nosso mundo, a cada dia que passa mais complexo, caótico e irracional.

\section{Referências}

ALEXANDRE, H.; RAVAGNANI, H.B. Estruturas e fundamentos sociais: a leitura Honnethiana de Habermas. Trans/Form/Ação, Marília, v. 36, n. 2, p. 155-178, 2013.

CASAGRANDE, C.A. G. H. Mead \& a Educação. Belo Horizonte: Autêntica, 2014. (Coleção Pensadores \& Educação). 
DALBOSCO, C.A. Pragmatismo, teoria crítica e educação. Campinas: Autores Associados, 2012.

FLICKINGER, H. A teoria do reconhecimento na práxis pedagógica: a exemplos de conflitos entre diretrizes ético morais. Espaço Pedagógico, v. 18, n. 2, p. 220-233, 2011.

HABERMAS, J. Pensamento pós-metafísico: Estudos Filosóficos. Rio de Janeiro: Tempo Brasileiro, 1990.

Teoria do agir comunicativo: racionalidade da açáo. São Paulo: WMF Martins Fontes, 2012a. v. 1.

- Teoria do agir comunicativo: sobre a crítica da razão funcionalista. São Paulo: WMF Martins Fontes, 2012b. v. 2.

HONNETH, A. Educação e esfera pública democrática: um capítulo negligenciado da filosofia política. Civitas, v. 13, n. 3, p. 544-563, 2013.

Luta por reconhecimento: a gramática moral dos conflitos sociais. São Paulo: Editora 34, 2003.

MEAD, G.H. Mind, Self \& Society: from the Standpoint of a Social Behaviorist. 19. ${ }^{\text {ed }}$. Chicago: University of Chigago Press, 1974.

PENITENTE, L. Notas sobre a presença de Mead na obra de Habermas. Trans/Form/ Ação, Marília, v. 36, p. 205-220, 2013.

Recebido em 31 de julho de 2016.

Aprovado em 30 de maio de 2017. 